\title{
WestVirginiaUniversity。
}

Department of Economics

Working Paper Series

\section{Out of the Outhouse: The Impact of \\ Place-Based Policies on Dwelling \\ Characteristics in Appalachia}

Daniel S. Grossman

Brad R. Humphreys

Jane E. Ruseski

Working Paper No. 17-10

This paper can be found at the College of Business and Economics Working Paper

Series homepage: 


\title{
Out of the Outhouse: The Impact of Place-Based Policies on Dwelling Characteristics in Appalachia
}

\author{
Daniel S. Grossman* \\ West Virginia University \\ Brad R. Humphreys ${ }^{\dagger}$ \\ West Virginia University \\ Jane E. Ruseski ${ }^{\ddagger}$ \\ West Virginia University
}

April 10, 2017

\begin{abstract}
The Appalachian Regional Commission (ARC) administers and partially funds investment projects designed to improve economic conditions in the Appalachian Region, an area of persistent poverty and reduced economic opportunity in the eastern US in and around the Appalachian mountains. Previous research on the effectiveness of ARC programs is mixed. We analyze the impact of ARC investment projects related to expanding sewerage and waste water treatment on dwelling characteristics. Results from a difference-in-differences model using a quasi experimental approach show that ARC investment projects improved access to running water, and increased sewer hook-ups and indoor bathrooms in dwellings.
\end{abstract}

JEL Codes: R5; R23; I1; H2

Keywords: Appalachian Region; place-based policy; infrastructure investment

*Department of Economics, College of Business and Economics, PO Box 6025, Morgantown WV 265066025, 304-293-7860; daniel.grossman@mail.wvu.edu

${ }^{\dagger}$ Department of Economics, College of Business and Economics, PO Box 6025, Morgantown WV 265066025; 304-293-7871; brhumphreys@mail.wvu.edu

${ }^{\ddagger}$ Department of Economics, College of Business and Economics, PO Box 6025, Morgantown WV 265066025; 304-293-7835; jeruseski@mail.wvu.edu 


\section{Introduction}

In 1965, Congress passed the Appalachian Redevelopment Act (ARA), which was signed into law by President Lyndon B. Johnson. This legislation created the Appalachian Regional Commission (ARC), a federal agency charged with improving economic conditions in a contiguous set of more than 400 counties spread across 13 states in the eastern US in or adjacent to the Appalachian mountains. This region has long been characterized by extreme poverty and other undesirable economic outcomes. Since 1965, ARC has administered and partially funded thousands of economic development projects, from large scale highway construction to small-scale, small-scope local planning initiatives. From 1965 through 2013, more than $\$ 25$ billion in ARC funding has gone toward investment projects to improve the lives of residents of the Appalachian Region.

A number of papers have assessed the impact of ARC investment on numerous economic outcomes in the Appalachian Region. Poole et al. (2015) undertook a comprehensive assessment of the effect of ARC investment on economic outcomes like poverty, educational attainment, and employment, as well as mortality rates, disease prevalence and health insurance coverage. The results were mixed; counties that received specific ARC investment funds grew somewhat faster than counties that did not receive similar investment funds, but the impact was uneven across the region. Results from a regional input-output model showed substantial direct, indirect, and induced economic benefits across the region, but those results cannot be easily mapped into economic outcomes for individual residents of the region. Other research has also found mixed results associated with ARC investment projects. Isserman and Rephann (1995) found evidence of substantial positive growth effects using matched-county approach while Glaeser and Gottlieb (2008) found no evidence of positive growth effects using a standard difference-in-differences approach.

Relatively little research has addressed the impact of ARC investment projects on individual economic outcomes. Lane et al. (2012) found that counties in the region had greater disparities in health costs, health care coverage, and health care access than other counties in the US in 2005, but these outcomes were not linked to any specific ARC projects. Stephens and Partridge (2011) found that self-employment in counties in the region was related to higher employment and income growth, suggesting entrepreneurship as a viable economic development tool in Appalachia. Poole et al. (2015) analyzed county level outcomes over time using a quasi experimental approach and found some evidence of improvements in a number of outcomes; these results were not linked to any specific ARC investment projects, and did not control for other county-level factors that could affect economic outcomes.

We analyze the effect of water, sewerage and sanitation-related ARC investment projects on individual economic outcomes like the presence of indoor plumbing and running water in dwellings over the period 1970-1990 using a quasi experimental (QE) approach. We use data from the decennial Census on dwelling characteristics matched with detailed data on the location and timing of ARC administered and funded investment projects related to water systems, sewer systems, and waste water treatment.

Prior to the formation of ARC, many Appalachian residents lacked access to running water and indoor plumbing, and ARC administered and partially funded many investment projects aimed at expanding access to public water and sewerage systems, and expanding local capacity to treat waste water. Access to clean water and modern sanitation have been 
linked to improved economic outcomes in many settings (Marx et al., 2013).

We estimate difference-in-differences models explaining variation in dwelling characteristics like sewer hook-ups, running water, and indoor bathrooms in counties in Appalachia where ARC administered programs occurred relative to other US counties. The results indicate that ARC investment projects had a clear effect on sanitation-related characteristics of dwellings in counties with ARC projects. Individual dwellings in these counties were more likely to have sewer hook-ups, running water, and indoor bathroom facilities in the 14 years after an ARC investment project was initiated in a county relative to other counties. Funding health-related infrastructure projects like these does not guarantee that individual dwellings will benefit from this improved infrastructure. Ashraf et al. (2016) show that the "last mile" problem applies to health-related infrastructure investments in that poor people often do not connect their homes to improved sanitation-related infrastructure. Improvements in sanitation-related dwelling characteristics enhanced the day-to-day life of residents of Appalachia, who did not have to use outhouses or rely solely on wells as a source of water, and indicate that ARC-related water and sewerage projects overcame the "last mile" problem in this setting.

\section{The Appalachian Regional Commission}

Appalachia, a mountainous region in the eastern United States, can be characterized as a region with substantial and persistent poverty and slow economic development. Over the period 2009-2013 the average poverty rate was 15.4\% in the United States and 17.0\% in Appalachia, or $110.8 \%$ of the U.S. average. ${ }^{1}$ The Appalachian Region lagged far behind the rest of the country in many areas when ARC was formed in the late 1960s. One such area was indoor plumbing in dwellings. Based on data from the 1970 Census, $13.6 \%$ of households in the Appalachian Region lived in dwellings lacking complete plumbing facilities; the US average outside Appalachia in 1970 was 6.9\% (Poole et al., 2015).

Because of persistent economic disparities, the Appalachian Regional Commission (ARC), a federal-state initiative to foster economic development and reduce poverty in the region, was created in 1965 by the Appalachian Regional Development Act and 420 counties in 13 states (New York, Pennsylvania, Ohio, West Virginia, Maryland, Kentucky, Virginia, Tennessee, North Carolina, Mississippi, Alabama, Georgia, and South Carolina) lying in the Appalachian mountain range were officially designated as the Appalachian Region. Only one state, West Virginia, lies entirely in the region. $42 \%$ percent of the population in the Appalachian Region resides in rural areas, compared to 20 percent of the national population. Figure 1 shows the counties in Appalachia, and the surrounding states.

ARC was charged with improving economic conditions in the Appalachian Region, helping the Region reach socioeconomic parity with the rest of the US, and improving the quality of life of residents of the Region. ARC operates to meet several specific goals: improve physical accessibility, develop the economy while reducing dependence on extractive industries, and enhance residents' capability to achieve economic prosperity. ARC meets these goals primarily by funding investment projects throughout the Region. From 1965 through 2013, ARC funded more than $\$ 25$ billion in public investment projects throughout the Region

\footnotetext{
${ }^{1}$ http://www.arc.gov/reports/custom_report.asp?REPORT_ID=60, accessed June 17, 2015.
} 


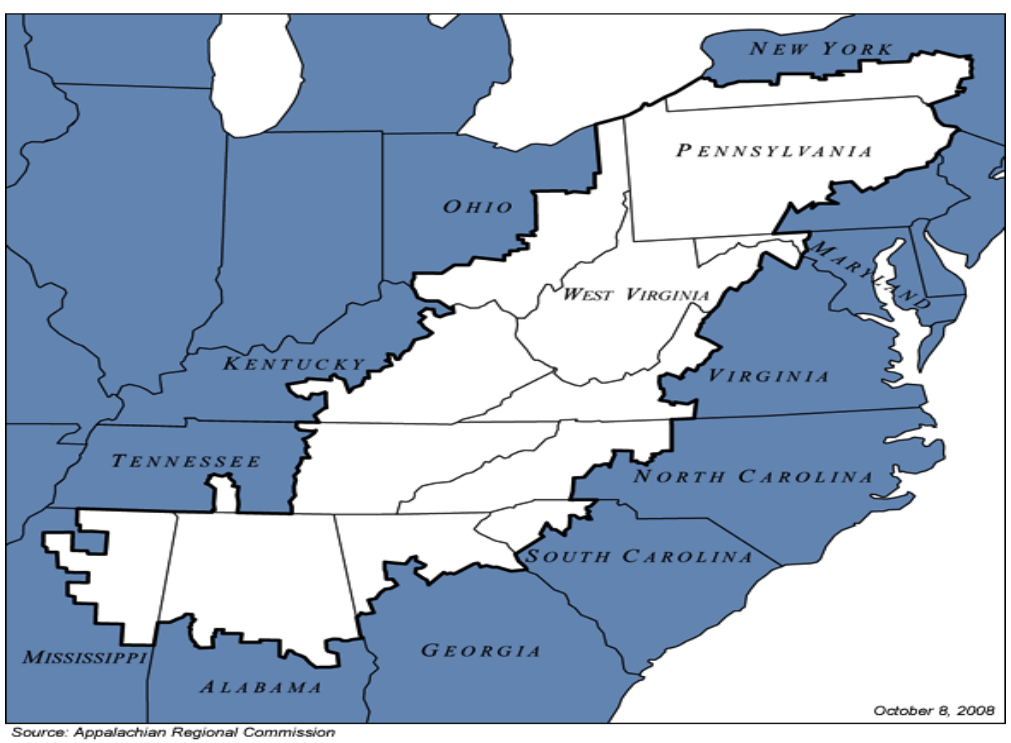

Figure 1: The Appalachian Region

(Poole et al., 2015). Much of this investment spending focused on building roads and highways in order to meet the goal of improving physical accessability. $\$ 3.8$ billion in federal funds have gone to non-highway-related investment projects. ARC investment projects also attract substantial matching funds from other federal, state, and local governments. The $\$ 3.8$ billion in non-highway investment was matched by $\$ 9$ billion in additional funding from other federal government agencies and other levels of government.

$\mathrm{ARC}$ investment projects are administered at the federal level. The investment project funding selection process is decentralized through a process that gives states some control over the allocation of their ARC funding. Potential investment projects are submitted to states in the initial phase of the process through which projects are funded. Each state assesses the merits of each project, based on the state's ARC funding priorities, and then the governor's office forwards acceptable project proposals to ARC, where their contribution to ARC's strategic plan is assessed (Davis et al., 2008). This funding approval process generates an even distribution of investment projects within states, and adds an idiosyncratic element to the location and timing of funded investment projects.

ARC's non-highway related investment projects include business development, child development, housing, health and health care, research and evaluation, infrastructure, and others. We focus on ARC funded projects related to sewerage systems, water systems, and waste water treatment projects. These represent large scale infrastructure projects focused on community sewerage and water systems, not on improvements to individual residences. Many of the dwellings in the Appalachian Region lacking complete plumbing facilities had well water and outhouses.

An absence of, or reduced access to, adequate sewer and water systems has been linked to a number of negative health and sanitation problems (Marx et al., 2013). These negative outcomes can result from direct exposure to bacteria, contamination of drinking water, or 

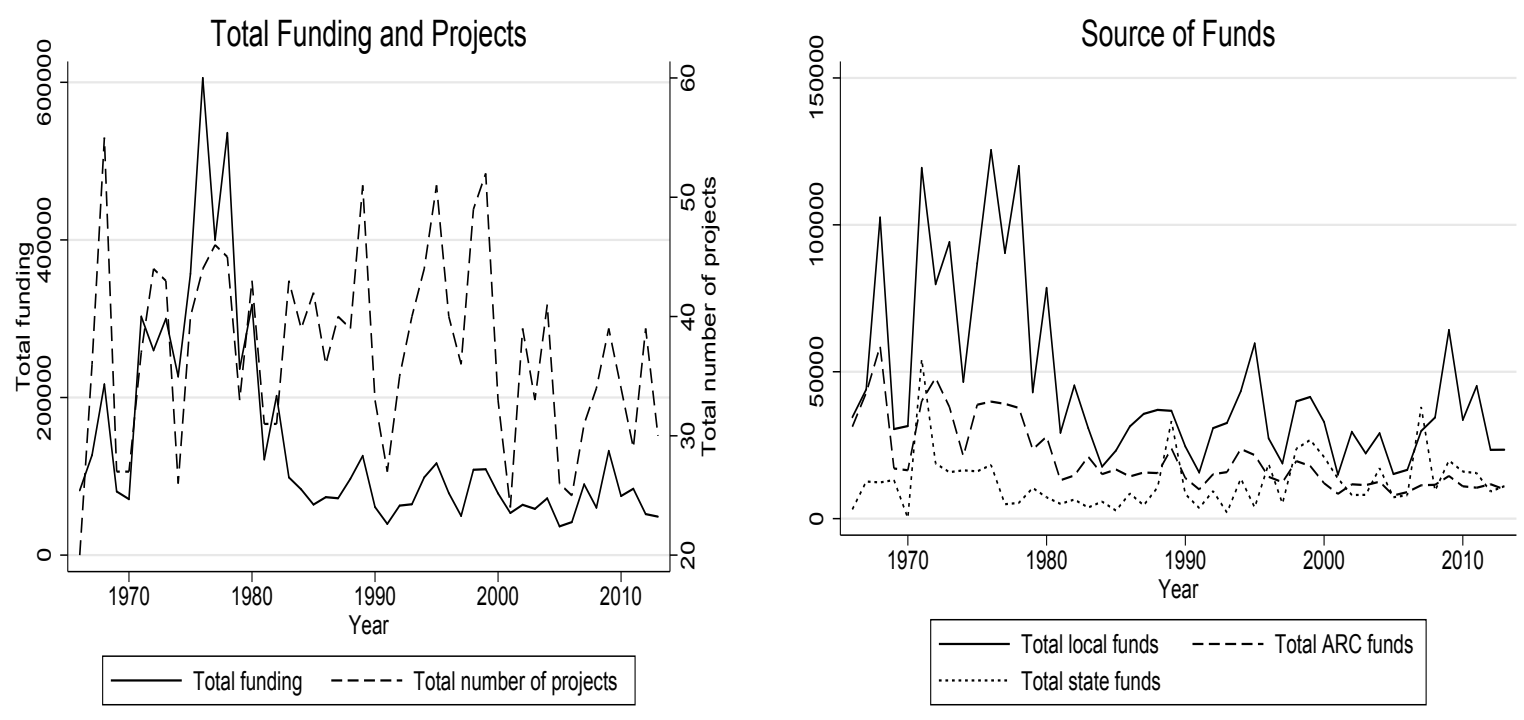

Figure 2: ARC Sewerage and Water Project Investment, Thousands of Real 2013 Dollars

other indirect effects. ARC funded investment projects related to water and sewerage include funds for the construction of local sewage treatment plants, extensions of sewer systems into rural areas, upgrading existing sewer systems, and other projects like planning new or expanded water or sewer systems. This analysis links large-scale ARC-funded projects with changes in the characteristics of individual dwellings in Appalachia, furthering understanding of the impact of ARC projects on the well being of individual Appalachian residents.

ARC publishes an annual list of funded projects that includes project titles, project descriptions, the county or counties affected by the project, and details about funding for these projects. The funding details include funds from ARC, total funds from local governments, total funds from state government, and the total expenditure on each project. Figure 2 summarizes key aspects of ARC-related funding sewerage investment projects over the period 1966-2013. The graph on the left shows total annual spending on investment in sewerage, in thousands of real 2013 dollars, and the total number of investment projects funded in each year.

On average, total annual spending on investment projects related to water and sewerage was about $\$ 141.5$ million in real 2013 dollars. However, total annual spending on such projects was substantially higher from 1966 until the early 1980s than in later years. Peak ARC-related investment in water and sewerage projects occurred between 1976 (\$605.5 million) and 1978 (\$535.8 million).

ARC funded about 37 investment projects related to water and sewerage every year over this period. The year-to-year variation in the number of projects funded was relatively large. Only 20 projects were funded in 1966; more than 50 projects were funded in 1968, 1989, and 1995.

On Figure 2, the graph on the right shows the source of funds used for ARC-sponsored water and sewerage investment projects. Local government funds constituted the largest source for these investment projects. Local government sources accounted for about $\$ 45$ 
million in investment in each year. ARC funds accounted for about \$20.6 million and state funds accounted for about $\$ 12.6$ million. Local and ARC funds were higher over the period 1966-1980 and declined in later years. State funds were somewhat higher in the 1970s, but have remained relatively constant over time.

Figure 3 shows the spatial and temporal distribution of investment projects administered by ARC over the period 1966-2013. All 13 states containing ARC counties are shown on Figure 3. Lightly shaded counties are ARC counties that did not have an ARC administered water or sewerage investment project in the decade shown. Dark shaded counties had one or more ARC administered projects during the decade. Note that while counties are identified on Figure 3, these investment projects are not typically county wide in scope. Most of the water and sewerage investment projects are focused on a single community or location in a county.

\section{The Effectiveness of Place-based Policies}

ARC represents a place-based economic policy, since it is targeted at creating new economic development in a specific region of the country. The literature contains substantial disagreement about the appropriateness, and effectiveness of place-based economic policies. According to Glaeser and Gottlieb (2008), the existence of mobility-driven spatial equilibrium, where individuals move to locations in a way to equilibrate utility across space, means that place-based policies will not increase social welfare. Instead, place-based policies distort prices and lead households and businesses to make inefficient locational choices.

Glaeser and Gottlieb (2008) also present evidence that ARC was not an effective placebased policy. Their study creates an analysis sample of counties that include all counties in the 13 states comprising ARC, except for counties within $90 \mathrm{~km}$ of the coast. In the regression analysis, ARC counties are "treated" and non-ARC counties constitute the control group. Using Census data, Glaeser and Gottlieb (2008) show that population growth and growth in real income per capita in ARC counties was not different from the growth rate in non-ARC counties over the period 1970-2000, after controlling for pre-ARC population and income per-capita. Glaeser and Gottlieb (2008) also argue that the $\$ 13$ billion in ARC spending spread over a large area over a long period of time was not sufficient to generate any tangible economic growth in the region.

Other evidence suggests that ARC represents a successful example of place-based policy. Isserman and Rephann (1995) use propensity score matching (PSM) to match ARC counties with counties outside Appalachia with similar characteristics. Their matching procedure used information on distance from cities, population, presence of interstate highways, indicators of the structure of the local economy, and several different types of income. Isserman and Rephann (1995) conclude that many ARC counties grew faster than their "twinned" control counties, in terms of population, total income, per capita income, and total earnings, from the late 1970s until the early 1990s.

Place-based policies can be effective in cases where mobility of households is too low to generate spatial equilibrium. Spatial frictions, in the form of monetary or psychic costs of moving to a different location, represent one reason for low household mobility. Substan-

tial evidence of spatial frictions exist, much of which pertains to Appalachia (Hughes and 
Figure 3: ARC Water \& Sewerage Projects by County and Decade
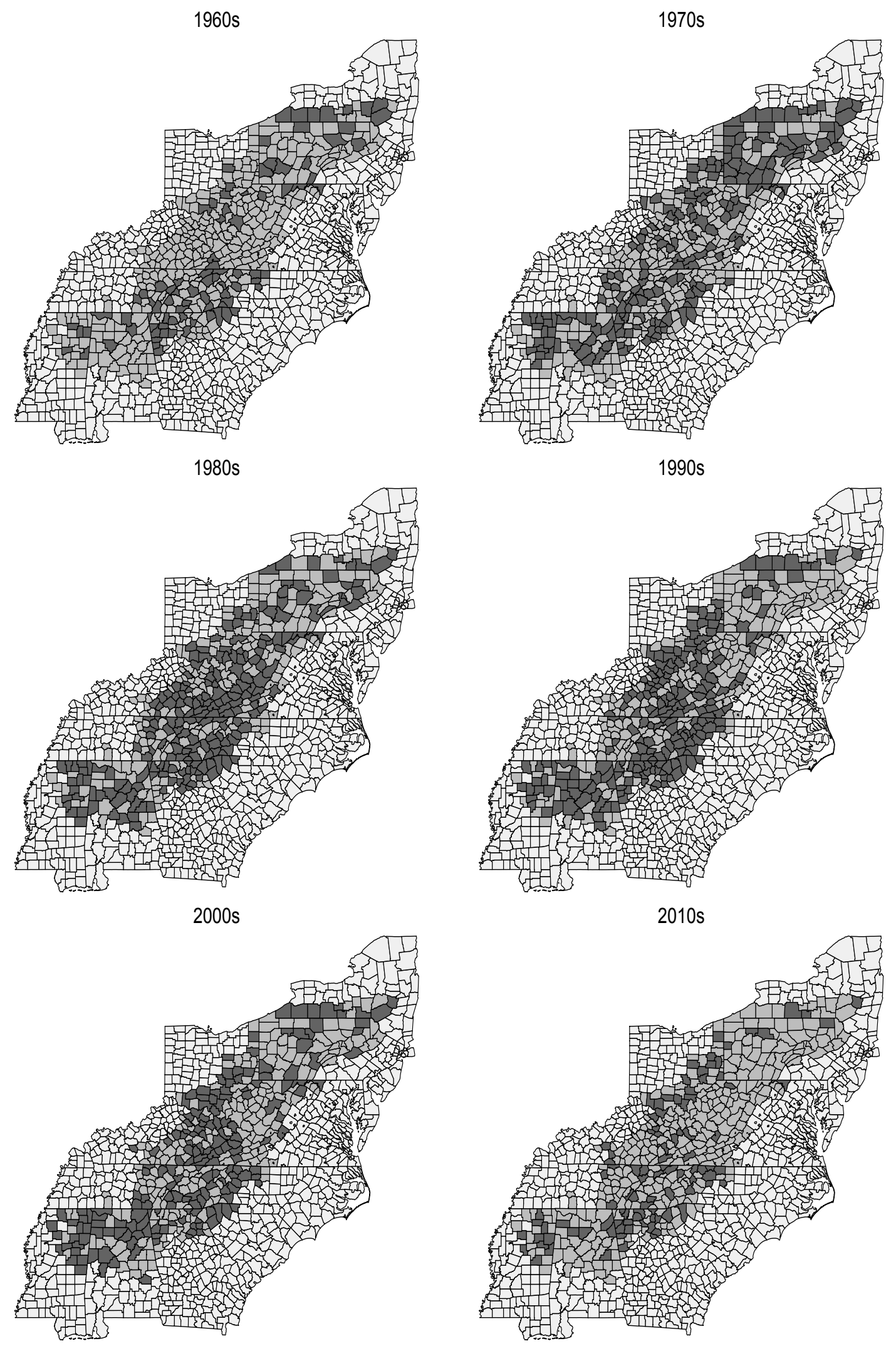
McCormick, 1994; Nord, 1998; Partridge and Rickman, 2008; Betz and Partridge, 2013). The presence of spatial frictions, and the resulting low mobility of households, suggests that place-based policies should also be evaluated based on their impact on both individuals and relatively fixed economic outcomes, for example dwellings. In the empirical analysis described below, we analyze the impact of ARC investment projects on the characteristics of dwellings in ARC counties.

\section{Empirical Analysis}

\section{Methods}

We use several empirical techniques to investigate the impact of ARC investment projects. The primary empirical analysis uses a difference-in-differences method to investigate the effect of ARC-funded water and sewerage projects on the number of dwellings having a complete indoor bathroom, running water, and having a sewage hookup in a county. This model takes the form:

$$
Y_{c t}=\alpha_{0}+\beta_{1} A R C_{c}+\beta_{2} \text { Post }_{t}+\beta_{3} A R C * \text { Post }_{c t}+X_{c t}^{\prime} \beta_{4}+\lambda_{c}+\gamma_{t}+\epsilon_{c t}
$$

where $Y_{c t}$ represents the proportion of dwellings without one of three different conditions (no sewage hookup, no running water, or no indoor bathroom) in county $c$, in year $t . A R C_{c}$ is an indicator for whether a county ever received ARC funds during the sample period, and Post equals 1 for all years between 1980 and 1988, but 0 for $1970 .^{2}$ Our main parameter of interest is $\beta_{3}$, the coefficient on the interaction of $A R C$ and Post. This is the parameter that captures the difference-in-differences, or the causal interpretation of the ARC investment program on outcomes of interest. We include county level fixed effects, $\lambda_{c}$, which account for time invariant differences of observable and unobservable characteristics. $\gamma_{t}$ is a set of year fixed effects. Technically, these county and year fixed effects subsume the main effects of $A R C_{c}$ and Post $_{t}$, but we include these covariates in Equation (1) for completeness. We cluster correct the estimated standard errors at the county level to account for serial correlation of unobservable factors affecting dwelling characteristics within counties.

In subsequent analyses, we include state by year fixed effects as well as county fixed effects. This model specification controls for other state level policy changes affecting state residents, including Medicaid implementation and income assistance programs. Finally, we include a vector of demographic characteristics of the county as of 1960 interacted with linear time trends and annual county-level per capita expenditures on retirement and disability programs, public assistance transfers, and Medicare from the Bureau of Economic Analysis Regional Information System.

Because we do not have data on dwelling characteristics from before 1970, we perform a number of additional sensitivity checks to explore the plausibility of our results in which we assume all data from 1970 come from a period before ARC existed. These sensitivity analyses essentially loosen and tighten assumptions about when each program was implemented and

\footnotetext{
${ }^{2}$ Although the ARC investment program began in 1965, this specification defines 1970 as a preprogram year. We do so because of data limitations in that the Census did not report data on dwelling characteristics before 1970. We perform a number of specification checks which we describe below.
} 
when we should expect to see an effect of these programs on dwelling characteristics in terms of sewage hookups, bathrooms, running water, and heating and cooling systems.

Recall that we have data at three points in time for this analysis: 1970, 1980, and 1990. As such, we first define the difference-in-differences parameter equal to 1 in 1970 if the initial ARC project was implemented in 1960 (for 1980 and 1990, the respective cut offs would be 1970 and 1980) and zero if it was implemented post-1960. This first specification should underestimate the treatment effect in that it assumes an ARC project will not affect housing characteristics in treated counties for a full decade. We estimate the same model, varying the definition of treatment for values $i=0, \ldots, 9$ such that for $i=9$ we set the differencein-differences parameter equal to 1 in 1970 if the initial ARC project was implemented in 1969 (rather than 1960). We demonstrate that our results follow the expected pattern, becoming stronger as we get closer to defining the treatment correctly. While this cannot fully demonstrate the validity of our specification, lacking a full lookback period or annual data, it provides suggestive evidence in support of our results properly capturing the effect of $\mathrm{ARC}$ projects on dwelling characteristics.

We do not expect the ARC investment projects to affect heating and cooling systems, as the ARC administered and funded projects did not focus on these as outcomes. In essence, assessing the impact of ARC funded water and sewerage projects on individual dwelling heating and cooling systems can be thought of as falsification tests, in which we would not expect ARC implementation to have an effect. We estimate these models in two ways.

First, we only analyze ARC administered projects associated with only water and sewerage projects. This analysis will capture the effect of projects specifically designed and implemented in a given year to improve local sanitation. In our second specification, we analyze all ARC administered projects, not just those limited to sewage and waste water systems. Because money is fungible, by receiving federal funds for a project, areas may have been able to shift money they had planned to spend on an ARC project to an unrelated water or sewage project.

We employ a quasi experimental (QE) approach to compare outcomes in counties in the Appalachian Region that received ARC funding for development projects to counties located in other parts of the country. The QE approach has been used extensively to analyze the effects of government programs in Appalachia (Isserman and Merrifield, 1982; Isserman and Rephann, 1995). The process of selecting control counties in the QE approach involves a number of complications. Feser (2013) discusses these issues.

Isserman and Merrifield (1982) and Isserman and Merrifield (1987) use an heuristic approach to select control counties; Rephann and Isserman (1994), Isserman and Rephann (1995), and a number of subsequent papers, use Mahalanobis distances to assess the similarity between treatment areas and potential control areas for a vector of matching variables. Recently, propensity score matching has been used to identify control areas when assessing the impact of public economic development programs (Glasmeier and Farrigan, 2007).

To account for the fact that the Appalachian region as a whole differs substantially from the rest of the US, and create a control group for the QE analysis, we use a new approach, the entropy balance method (Hainmueller, 2012). The basic idea behind this method is to create a sample of weighted control observations that is nearly identical to the treated sample on observable characteristics including specific balance conditions incorporating information about sample moments. The assumption, as usual, is that if control areas are similar to 
treated areas on observable characteristics, these areas will also be similar on unobservable characteristics.

Poole et al. (2015) used nearest neighbor matching, kernel-based propensity score matching, and Mahalanobis distance matching when assessing the overall impact of ARC projects. Smith and Todd (2005) discuss limitations of propensity score matching for policy evaluation because of sensitivity to the choice of matching variables. Using monte carlo simulations, Hainmueller (2012) shows that entropy balancing has superior small sample properties than propensity score and Mahalanobis distance matching.

Entropy balancing generates a balanced sample by creating a weighting scheme that reweights control observations so that they are perfectly balanced compared to treated individuals based on the specified moments. These weights are then incorporated into the empirical model specified above, Equation (1), as a survey weight. After weighting, the treatment indicator is orthogonal to the covariate moments included in the entropy balancing exercise.

If $w_{i}$ are the chosen weights for a control unit, the entropy balancing reweighting can be captured by the following:

$$
\min H(w)=\sum_{i \mid D=0} h\left(w_{i}\right)
$$

subject to

$$
\begin{gathered}
\sum_{i \mid D=0} w_{i} c_{r i}\left(X_{i}\right)=m_{r} \text { with } \quad r \in 1, \ldots, R \text { and } \\
\sum_{i \mid D=0} w_{i}=1 \text { and } \\
w_{i} \geq 0 \quad \forall \quad i \text { such that } D=0,
\end{gathered}
$$

where $h(\cdot)$ is a distance metric and $c_{r i}\left(X_{i}\right)$ is a set of $R$ balance constraints imposed on the covariate moments of the reweighted control group. These balance constraints force weighted control and treatment covariate means to be equal. This is similar to a generalized propensity score weighting approach. The main difference, and strength, is that this approach does not require the econometrician to first estimate weights, then iteratively check whether treatment and control covariates balance (Deb and Vargas, 2016).

Summary statistics for the unweighted sample of all non-ARC US counties and the entropy balanced samples are shown in Table 1 for all covariates used in the entropy balancing approach. As this table clearly shows, before using entropy balancing, ARC counties differ substantially from other US counties for all of these observable characteristics. However after entropy balancing, the reweighted treatment and control counties do not differ at all. 
Table 1: Entropy Balancing ARC and non-ARC Counties Using 1959-1965 Data

\begin{tabular}{|c|c|c|c|c|}
\hline & \multicolumn{2}{|c|}{ Pre Balance } & \multicolumn{2}{|c|}{ Post Entropy Balance } \\
\hline & $\mathrm{ARC}$ & Non-ARC & ARC & Non-ARC \\
\hline Log Population 1959 & 10.15 & 9.842 & 10.15 & 10.15 \\
\hline State Local Per Capita Earnings 1959 & 40626.7 & 49695.5 & 40626.7 & 40627.0 \\
\hline Rate of Growth Total Income 1959 & 0.442 & 0.347 & 0.442 & 0.442 \\
\hline Population Growth 1959 & -0.0298 & 0.0449 & -0.0298 & -0.0298 \\
\hline Population Density 1959 & 87.02 & 193.1 & 87.02 & 87.02 \\
\hline Distance to 25k City 1960 & 32.65 & 46.69 & 32.65 & 32.65 \\
\hline Distance to $100 \mathrm{k}$ City 1960 & 68.29 & 97.98 & 68.29 & 68.29 \\
\hline Distance to $250 \mathrm{k}$ City 1960 & 106.8 & 142.4 & 106.8 & 106.8 \\
\hline Distance to 500k City 1960 & 187.8 & 272.8 & 187.8 & 187.8 \\
\hline Distance to $1000 \mathrm{k}$ City 1960 & 359.5 & 529.7 & 359.5 & 359.5 \\
\hline Freeway Present & 0.432 & 0.425 & 0.432 & 0.432 \\
\hline Share of Income (SOI) Retail 1959 & 0.0878 & 0.102 & 0.0878 & 0.0878 \\
\hline SOI Transportation 1959 & 0.0448 & 0.0444 & 0.0448 & 0.0448 \\
\hline SOI Manufacturing 1959 & 0.217 & 0.126 & 0.217 & 0.217 \\
\hline SOI Services 1959 & 0.0642 & 0.0677 & 0.0642 & 0.0642 \\
\hline SOI Construction 1959 & 0.0336 & 0.0421 & 0.0336 & 0.0336 \\
\hline SOI Farming 1959 & 0.105 & 0.161 & 0.105 & 0.105 \\
\hline SOI Transfers 1959 & 0.121 & 0.0993 & 0.121 & 0.121 \\
\hline SOI Dividends and Rent 1959 & 0.0767 & 0.121 & 0.0767 & 0.0767 \\
\hline SOI Military Earnings 1959 & 0.00721 & 0.0168 & 0.00721 & 0.00721 \\
\hline SOI Federal EArnings 1959 & 0.0219 & 0.0277 & 0.0219 & 0.0219 \\
\hline SOI State and Local Earnings 1959 & 0.0701 & 0.0753 & 0.0701 & 0.0701 \\
\hline SOI Wholesale Earnings & 0.0206 & 0.0253 & 0.0206 & 0.0206 \\
\hline \% Population in Poverty 1959 & 19.04 & 14.10 & 19.04 & 19.04 \\
\hline \% Population Under 171960 & 37.93 & 37.42 & 37.93 & 37.93 \\
\hline \% Population Under 651960 & 9.808 & 10.90 & 9.808 & 9.808 \\
\hline \% Population Black 1960 & 6.181 & 8.914 & 6.181 & 6.181 \\
\hline Observations & 391 & 2360 & 391 & 2343 \\
\hline
\end{tabular}

Source: Entropy matching (Hainmueller 2012) using county-level characteristics before the ARC program began. 


\section{Data}

We use data from two sources in the empirical analysis: ARC administrative data describing every non-highway investment project administered by ARC since 1965, and decennial Census data from 1970 to 1990 at the county level.

First, we use administrative data from ARC describing each project that the Commission administered and funded between 1965 and 2015. These data include the universe of projects administered and funded at least in part by ARC. The records identify all counties included in each project, the year the project was initiated, and a description of the project goal. We classify projects in two ways: (1) all ARC projects; and (2) ARC projects related to water and sewage. The first classification is self-evident. We include any project that included the terms "sewage," "sewer," "wastewater," "waste water," "water treatment," or "water system" in the project title in the second classification.

Finally, we use Decennial census data from 1970 to 1990. These data provide county level information about the percentage of homes without running water, without a sewage hookup, without air conditioning, without an indoor bathroom, and without heat. These data are only available every 10 years and are not included in the census before 1970. This prevents us from performing a pre-trend analysis. However, the rates of sewage hookups and indoor bathrooms in ARC counties has increased substantially since 1970 (Poole et al., 2015). In 1970, nearly 14 percent of homes in the Appalachian Region lacked complete plumbing facilities compared to just 7 percent of homes in other regions. Because of the large number of water and sewage related projects carried out using ARC funds, we investigate the effect of the timing of these project implementations on the presence of a sewage hookup, indoor plumbing, and running water in individual dwellings in Appalachia.

\section{Results}

In Table 2, we present parameter estimates and estimated standard errors for the coefficient $\left(\beta_{3}\right)$ on the interaction of $A R C$ and Post in Equation (1). This parameter captures the causal effect of an ARC funded water or sewage project in a county on dwelling characteristics in that county. Recall that in our basic difference-in-difference model specification, $A R C$ is an indicator variable equal to 1 if county ever received ARC funds for a water or sewage project between 1970 and 1988 that is interacted with Post $_{t}$, an indicator variable that equals 1 for all years 1980 to 1988 and 0 for 1970. We focus on the time period between 1970 and 1988 because most of ARC funding for sewage projects was concentrated during this time period and because we have data on dwelling characteristics for 1970, 1980, and 1990.

Table 2 contains estimates of the parameter of interest, $\hat{\beta}_{3}$, and estimated standard errors for three dwelling characteristics: sewer hook-ups, running water, and indoor bathrooms. The results in the first three columns are based on the full sample of counties without entropy balancing (hereafter "unweighted" results). Results in the first column come from models that include county and year fixed effects; results in column two add state-by-year fixed effects to the empirical model; results in column 3 add county level covariates as of 1960 to the empirical model.

The unweighted results generally indicate that ARC water and sewage projects reduced the number of dwellings in treated counties without sewer hookups, running water, and 
Table 2: Regression Results - Effect of ARC Programs on Dwelling Characteristics

\begin{tabular}{|c|c|c|c|c|c|c|}
\hline & \multicolumn{3}{|c|}{ Not Entropy Balanced } & \multicolumn{3}{|c|}{ Entropy Balanced } \\
\hline \multicolumn{7}{|c|}{ Characteristic: Dwellings with no sewer hookup } \\
\hline$\hat{\beta}_{3}$ & $\begin{array}{c}-0.087^{* * *} \\
(0.007)\end{array}$ & $\begin{array}{c}-0.025^{* * *} \\
(0.006)\end{array}$ & $\begin{array}{c}-0.022^{* * *} \\
(0.004)\end{array}$ & $\begin{array}{c}-0.052^{* * *} \\
(0.008)\end{array}$ & $\begin{array}{c}-0.016^{* * *} \\
(0.006)\end{array}$ & $\begin{array}{c}-0.010^{* *} \\
(0.004)\end{array}$ \\
\hline \multicolumn{7}{|c|}{ Characteristic: Dwellings with no running water } \\
\hline$\hat{\beta}_{3}$ & $\begin{array}{c}-0.020^{* * *} \\
(0.003)\end{array}$ & $\begin{array}{c}-0.015^{* * *} \\
(0.003)\end{array}$ & $\begin{array}{c}-0.014^{* * *} \\
(0.003)\end{array}$ & $\begin{array}{c}-0.012^{* * *} \\
(0.004)\end{array}$ & $\begin{array}{c}-0.012^{* * *} \\
(0.003)\end{array}$ & $\begin{array}{c}-0.011^{* * *} \\
(0.003)\end{array}$ \\
\hline \multicolumn{7}{|c|}{ Characteristic: Dwellings with no indoor bathroom } \\
\hline$\hat{\beta}_{3}$ & $\begin{array}{c}-0.063^{* * *} \\
(0.007)\end{array}$ & $\begin{array}{l}-0.002 \\
(0.006)\end{array}$ & $\begin{array}{c}-0.011^{* * *} \\
(0.004)\end{array}$ & $\begin{array}{c}-0.025^{* * *} \\
(0.009)\end{array}$ & $\begin{array}{c}0.004 \\
(0.007)\end{array}$ & $\begin{array}{c}-0.008^{* *} \\
(0.004)\end{array}$ \\
\hline $\begin{array}{l}\text { Year, County FE } \\
\text { State x year FE } \\
1960 \text { Demographics }\end{array}$ & $\mathrm{X}$ & $\begin{array}{l}X \\
X\end{array}$ & $\begin{array}{l}X \\
X \\
X\end{array}$ & $\mathrm{X}$ & $\begin{array}{l}X \\
X\end{array}$ & $\begin{array}{l}X \\
X \\
X\end{array}$ \\
\hline
\end{tabular}

indoor bathrooms. The no sewer hookup and no running water results are robust across models but the no indoor bathroom results are somewhat sensitive to specification. However, taken together, an overall picture of ARC water and sewage projects having the desired effect of improving basic sanitation-related dwelling characteristics emerges.

The unweighted results do not account for the idea that counties in Appalachia differ from non-Appalachian counties. We address this possibility by using entropy balancing methods to create a control group that is nearly identical to the treatment group based on observable county characteristics. The entropy balanced results are shown in columns four, five and six on Table 2. As with the unweighted results, results in column four include county and year fixed effects; results in column five add state-by-year fixed effects to the empirical model; and results in column six add county level covariates as of 1960 to the empirical models.

The entropy balanced results are consistently weaker than the unweighted results across model specifications in that the parameter estimates are generally smaller. The results in the first 3 columns are biased because ARC counties are generally poorer than non-ARC counties. The entropy weighted sample results correct for this bias and still suggest that ARC investments in water and sewage projects reduced the number of dwellings in treated counties without sewer hookups, running water, and indoor bathrooms. The entropy weighted sample results can be interpreted as causal, and indicate that ARC administered water and sewer projects led to improved sanitary conditions in dwellings throughout Appalachia.

\section{Robustness and Falsification Tests}

A challenge we face in identifying an effect of ARC investment projects on dwelling characteristics is the lack of data on dwelling characteristics before 1970 and only observing dwelling characteristics in the decennial census years 1970, 1980 and 1990. We investigate 
the plausibility of our baseline difference-in-difference specification by altering assumptions about when an investment program was implemented and when we might expect the program to have an effect on dwelling characteristics. Table 3 contains the results for the entropy weighted sample and models including all covariates.

For each column on Table 3, the difference-in-difference indicator variable equals 0 if there was never an ARC water or sewage project before $19 \mathrm{ZX}$ where $X=0, \ldots, 9$. It equals 1 in 1970 (and all time periods thereafter until 1988) if an ARC project began in 196X or earlier and 1 in 1980 if the sewage project began in 197X or earlier. Because we only have three points in time in which we can measure access to sewer hookups, running water and indoor bathrooms, we test how sensitive our model is to alternative assumptions of how long it would take for an ARC program focused on water and sewerage to improve these outcomes. In essence, the specifications assume that the treatment effects occur closer to the project funding year as we move across the columns from (Z1) to (Z9), so that on the left hand side of the table we assume it takes nearly 9 years from initiating an ARC sewer or water project to see a treatment effect while the final column assumes treatment effects should appear one year after the project began. The results in the final column on Table 3 are the same as the results in the final column on Table 2. Moving from right to left across Table 3 moves the assumed treatment period farther back in time from the actual ARC program funding year. ${ }^{3}$

Table 3: Timing of ARC Project Indicator Variable, Entropy Balanced Sample

\begin{tabular}{|c|c|c|c|c|c|c|c|c|c|}
\hline & $(\mathrm{Z} 1)$ & $\begin{array}{l}\text { ff in Diff } \\
(\mathrm{Z} 2)\end{array}$ & $\begin{array}{c}\text { icator }=1 \\
(\mathrm{Z} 3)\end{array}$ & $\begin{array}{c}\text { ARC prog } \\
(\mathrm{Z} 4)\end{array}$ & $\begin{array}{l}\text { began in } \\
\text { (Z5) }\end{array}$ & $\begin{array}{l}\text { ZX or earl } \\
\quad(\mathrm{Z} 6)\end{array}$ & $\begin{aligned} \mathrm{Z}= & 60 \mathrm{~s}, 70 \mathrm{~s} \\
& (\mathrm{Z} 7)\end{aligned}$ & $(\mathrm{Z} 8)$ & (Z9) \\
\hline \multicolumn{10}{|c|}{ Characteristic: No Sewer Hookup } \\
\hline$\hat{\beta}_{3}$ & $\begin{array}{l}-0.004 \\
(0.004)\end{array}$ & $\begin{array}{l}-0.004 \\
(0.004)\end{array}$ & $\begin{array}{l}-0.004 \\
(0.004)\end{array}$ & $\begin{array}{l}-0.003 \\
(0.004)\end{array}$ & $\begin{array}{c}-0.004 \\
(0.004)\end{array}$ & $\begin{array}{c}-0.009^{* *} \\
(0.004)\end{array}$ & $\begin{array}{c}-0.009^{* *} \\
(0.004)\end{array}$ & $\begin{array}{c}-0.009^{* *} \\
(0.004)\end{array}$ & $\begin{array}{r}-0.010^{* *} \\
(0.004)\end{array}$ \\
\hline \multicolumn{10}{|c|}{ Characteristic: No Running Water } \\
\hline$\hat{\beta}_{3}$ & $\begin{array}{c}-0.005^{*} \\
(0.003)\end{array}$ & $\begin{array}{c}-0.005^{*} \\
(0.003)\end{array}$ & $\begin{array}{c}-0.007^{* *} \\
(0.003)\end{array}$ & $\begin{array}{c}-0.007^{* * *} \\
(0.003)\end{array}$ & $\begin{array}{c}-0.007^{* *} \\
(0.003)\end{array}$ & $\begin{array}{c}-0.010^{* * *} \\
(0.003)\end{array}$ & $\begin{array}{c}-0.011^{* * *} \\
(0.003)\end{array}$ & $\begin{array}{c}-0.010^{* * *} \\
(0.003)\end{array}$ & $\begin{array}{c}-0.011^{* * *} \\
(0.003)\end{array}$ \\
\hline \multicolumn{10}{|c|}{ Characteristic: No Indoor Bathroom } \\
\hline$\hat{\beta}_{3}$ & $\begin{array}{c}0.002 \\
(0.004)\end{array}$ & $\begin{array}{l}-0.000 \\
(0.004)\end{array}$ & $\begin{array}{c}-0.001 \\
(0.004)\end{array}$ & $\begin{array}{c}0.001 \\
(0.004)\end{array}$ & $\begin{array}{c}0.001 \\
(0.004)\end{array}$ & $\begin{array}{l}-0.004 \\
(0.004)\end{array}$ & $\begin{array}{l}-0.005 \\
(0.004)\end{array}$ & $\begin{array}{c}-0.007^{* *} \\
(0.004)\end{array}$ & $\begin{array}{c}-0.008^{* *} \\
(0.004)\end{array}$ \\
\hline
\end{tabular}

Source: Census data provides a measure of the percentage of residences in a county lacking each condition. For column year (Z1-Z9), the difference in differences indicator equals 0 if there was never an ARC Sewage project before 19ZX. It equals 1 in 1970 (and all time periods after) if an ARC water or sewage project began in 196X or earlier, and 1 in 1980 if an ARC water or sewage project began in $197 \mathrm{X}$ (where $\mathrm{Z}=7$ and $\mathrm{ZX}=$ column number) or earlier. Models include county, year and state-by-year fixed effects and county-level covariates from 1960 on.

The results on Table 3 follow the expected pattern in that they remain statistically significant and become stronger, or become statistically significant as the effect of treatment is assumed to occur closer to the ARC project funding year. The effects of ARC water and sewer projects on dwelling characteristics become statistically significant as the time between the project funding year and assumed treatment effect year get closer. For example, in the

\footnotetext{
${ }^{3}$ The estimates should be biased towards zero in columns (Z1) to (Z8) because these models attribute observations to the control group that had already implemented an ARC water or sewerage project, e.g. in column (Z1) counties that implemented water and sewerage projects in 1961 would receive 1 in 1970, but counties that began projects in 1962-1969 would not. Moving from right to left across Table 3 reduces this control group contamination.
} 
Table 4: Falsification Test - Effect of ARC Programs on Presence of Heating/Cooling Systems

\begin{tabular}{lcccccc}
\multicolumn{4}{c}{ Not Entropy Balanced } & \multicolumn{1}{c}{ Entropy Balanced } \\
\hline \multicolumn{1}{l}{ Characteristic: No Heating System } \\
\hline$\hat{\beta}_{3}$ & $\begin{array}{c}0.002^{* * *} \\
(0.001)\end{array}$ & -0.000 & 0.000 & $0.003^{*}$ & -0.000 & -0.001 \\
\multicolumn{1}{c}{$(0.001)$} & $(0.001)$ & $(0.002)$ & $(0.001)$ & $(0.001)$ \\
\hline \multicolumn{2}{l}{ Characteristic: No Air Conditioning } & & & & \\
\hline$\hat{\beta}_{3}$ & 0.005 & 0.005 & 0.004 & -0.000 & -0.006 & 0.002 \\
\multicolumn{1}{l}{$(0.008)$} & $(0.007)$ & $(0.007)$ & $(0.010)$ & $(0.007)$ & $(0.007)$ \\
\hline Year, County FE & $\mathrm{X}$ & $\mathrm{X}$ & $\mathrm{X}$ & $\mathrm{X}$ & $\mathrm{X}$ & $\mathrm{X}$ \\
State x year FE & & $\mathrm{X}$ & $\mathrm{X}$ & & $\mathrm{X}$ & $\mathrm{X}$ \\
1960 Demographics & & & $\mathrm{X}$ & & & $\mathrm{X}$ \\
\hline
\end{tabular}

model results shown on Table 3 with county and year fixed effects and county covariates included, $\hat{\beta}_{3}$ is negative but statistically insignificant in (Z1), (Z2), (Z3), (Z4) and (Z5) for sewer hookups but becomes statistically significant in (Z6) and remains significant while increasing in magnitude thereafter. These results suggest that the effects of sewer and water system projects begin to appear very soon after the project begins. A similar pattern can be seen for No Indoor Bathroom and No Running Water.

We perform a falsification test based on other observable dwelling characteristics. Recall that we interpret the presence of heating and cooling systems in dwellings as a characteristic that can be used as a falsification test because ARC water and sewage investment programs would not be expected to affect these dwelling characteristics. Table 4 shows the results of these falsification tests. Table 4 has the same format as Table 2. The three left columns contain results for the unweighted sample and the three right columns contain results from the entropy balanced sample. Additional covariates are added to the regression model when moving left to right across these columns.

From Table 4, the difference-in-difference estimates for the No Heating System models are more sensitive to specification in that they are positive, small in magnitude, and statistically significant in the model with county and year fixed effects but become statistically insignificant in the models that add state-by-year fixed effects and county-level covariates. The results for the No Air Conditioning models are positive but statistically insignificant in all models. These results support our idea that these dwelling characteristics serve as a falsification test and suggest that our results are properly capturing the effect of ARC sewage funding projects.

We also estimated an analogous set of unweighted and entropy balanced regression models using funding for any ARC projects, rather than funding specifically earmarked for water and sewage projects, to identify treated counties. These other ARC administered projects represent a wide array of local development projects from access road construction to computer purchase to funding for youth summer camps. These results are not presented here but are available on request. The results from these models are qualitatively similar but 
substantially weaker than the water and sewage specific results on Table 2 and Table 3 in terms of the estimated effect of these projects on dwelling characteristics in treated counties. The estimated parameters on the the difference-in-difference variables are generally not statistically different from zero. The overall finding that ARC funding for water and sewage projects is associated with reducing the number of dwellings without sewer hookups, indoor bathrooms, and running water lends support for place-based policies in areas with spatial frictions like Appalachia.

\section{Conclusions}

The Appalachian Regional Commission was established in 1965 to provide federal assistance to the mountainous region spanning thirteen states form New York to Mississippi in an effort to foster economic growth and reduce poverty. ARC identifies 5 overarching goals that include investing in critical infrastructure and increasing the health of residents to work and succeed in Appalachia. ${ }^{4}$ The establishment of, and continued existence of ARC, is an example of place-based economic policy since its focus is on a specific US region. There is general disagreement about the appropriateness and effectiveness of place-based economic policies, in general and specifically about ARC as an example of such a policy. This paper contributes to this debate by evaluating the impact of ARC investments, particularly in sewer and water treatment projects, on dwelling characteristics.

We focus on the impact of ARC administered and funded projects related to water, waste water, or sewage systems for three reasons. First, the Appalachian Region lagged far behind the rest of country in terms of complete indoor plumbing when ARC was established. Second, absence of or reduced access to adequate sewer systems, running water, and indoor bathrooms can lead to negative health outcomes. Third, most studies of the effectiveness of $\mathrm{ARC}$ as a place-based policy focus on economic outcomes like growth in per capita income and employment growth. This study provides some of the first evidence on the effect of ARC investments on economic outcomes like sanitation-related dwelling characteristics that potentially have a large effect on the well-being of residents of Appalachia.

Our results show that $\mathrm{ARC}$ administered and funded sewerage and water treatment projects reduced the proportion of households without sewer hookups, running water and indoor bathrooms in treated counties relative to the rest of the US. This is an important result, because the ARC projects were not targeted at individual dwellings; the ARC projects analyzed were system-level projects aimed at increasing local capacity to treat waste water, or to expand sewer and water mains in rural areas. The fact that these projects had an impact on sanitation-related dwelling characteristics represents evidence that relatively broad ARC administered projects can affect economic outcomes at the individual level, and that these programs overcame important "last mile" problems associated with health improving infrastructure investment projects identified by Ashraf et al. (2016).

Taken together, our results paint a nuanced picture of the effectiveness of ARC as a place-based policy. We find causal evidence that ARC succeeded in its early years at building critical infrastructure, and that these projects also had an effect on important sanitationrelated dwelling characteristics in Appalachia. These results add to the body of evidence that

\footnotetext{
${ }^{4}$ https://www.arc.gov/about/index.asp, accessed November 16, 2016.
} 
ARC investments are positively associated with economic outcomes like per capita income growth (Isserman and Rephann, 1995; Poole et al., 2015).

It is also possible that these ARC administered projects affected health in Appalachia. Improved local sanitation achieved through upgraded sewer systems and expansion of sewage and water treatment plants may lead to improved health outcomes, but evidence of this link may not be sufficiently strong to be detected in broad measures of health outcomes like age-adjusted mortality rates. Improved sanitation may need to occur in tandem with other improvements, like improved access to basic health care and preventative medicine in order to see a reduction in factors like mortality rates. Also, improving population health entails not only improving access to health care but also encouraging individuals to adopt and to maintain healthy lifestyles. Future research should thoroughly investigate links between ARC administered water and sewer projects and an array of health outcomes. 


\section{References}

Ashraf, N., Glaeser, E. L., and Ponzetto, G. A. (2016). Infrastructure, incentives, and institutions. American Economic Review, 106(5):77-82.

Betz, M. R. and Partridge, M. D. (2013). Country road take me home: Migration patterns in Appalachian America and place-based policy. International Regional Science Review, 36(3):267-295.

Davis, A. F., Maurer, R., Allen, J. E., Talbert, J., and Childress, M. (2008). Program evaluation of the Appalachian Regional Commissions health projects, 2004-2010. Technical report, Community and Economic Development Initiative of Kentucky.

Deb, P. and Vargas, C. (2016). Who Benefits from Calorie Labeling? An Analysis of its Effects on Body Mass. NBER Working Paper 21992, National Bureau of Economic Research, Inc.

Feser, E. (2013). Issermans impact: quasi-experimental comparison group designs in regional research. International Regional Science Review, 36(1):44-68.

Glaeser, E. L. and Gottlieb, J. D. (2008). The economics of place-making policies. Brookings Papers on Economic Activity, pages 155-239.

Glasmeier, A. K. and Farrigan, T. (2007). The economic impacts of the prison development boom on persistently poor rural places. International Regional Science Review, 30(3):274299.

Hainmueller, J. (2012). Entropy balancing for causal effects: A multivariate reweighting method to produce balanced samples in observational studies. Political Analysis, 20:2546.

Hughes, G. and McCormick, B. (1994). Did migration in the 1980s narrow the north-south divide? Economica, pages 509-527.

Isserman, A. and Rephann, T. (1995). The economic effects of the Appalachian Regional Commission: An empirical assessment of 26 years of regional development planning. Journal of the American Planning Association, 61(3):345-364.

Isserman, A. M. and Merrifield, J. (1982). The use of control groups in evaluating regional economic policy. Regional Science and Urban Economics, 12(1):43-58.

Isserman, A. M. and Merrifield, J. D. (1987). Quasi-experimental control group methods for regional analysis: An application to an energy boomtown and growth pole theory. Economic Geography, 63(1):3-19.

Lane, N., Konrad, R., and Ricketts, T. (2012). Health care costs and access disparities in Apppalachia. Washington, DC: Appalachia Regional Commission.

Marx, B., Stoker, T., and Suri, T. (2013). The economics of slums in the developing world. The Journal of Economic Perspectives, 27(4):187-210. 
Nord, M. (1998). Poor people on the move: County-to-county migration and the spatial concentration of poverty. Journal of Regional Science, 38(2):329-351.

Partridge, M. D. and Rickman, D. S. (2008). Place-based policy and rural poverty: insights from the urban spatial mismatch literature. Cambridge Journal of Regions, Economy and Society, 1(1):131-156.

Poole, K., Romitti, M., White, M., Feser, E., Mix, T., Gutschow, S., Buff, B., Arthur, R., Sun, W., Jackson, R., Lacombe, D., Piras, G., Sayago, J., Stair, C., Deskins, J., Ruseski, J., Christiadi, U., Bowen, E., Lego, B., and Manzi, P. (2015). Appalachia then and now: Examining the changes to the Appalachian Region since 1965. ARC report, Appalachian Regional Commission.

Rephann, T. and Isserman, A. (1994). New highways as economic development tools: An evaluation using quasi-experimental matching methods. Regional Science and Urban Economics, 24(6):723-751.

Smith, J. A. and Todd, P. E. (2005). Does matching overcome LaLonde's critique of nonexperimental estimators? Journal of Econometrics, 125(1):305-353.

Stephens, H. M. and Partridge, M. D. (2011). Do entrepreneurs enhance economic growth in lagging regions? Growth and Change, 42(4):431-465. 